\title{
طقوس بيليان باسير نوندوي \\ (استكشاف قيم الوسطية الدينية في الحكمة المحلية لمجتمع باسير)
}

\section{THE RITUAL OF BELIAN PASER NONDOI \\ (Exploring The Values of Religious Moderation in The Local Wisdom of Paser \\ Community)}

\author{
Hamsiati \\ Balai Penelitian dan Pengembangan Agama \\ Jl. AP. Pettarani No. 72 Makassar \\ Email: hamsiatib@gmail.com
}

Khaerun Nisa'

Balai Penelitian dan Pengembangan Agama

Jl. AP. Pettarani No. 72 Makassar

Email:kn.khaerunnisa@gmail.com

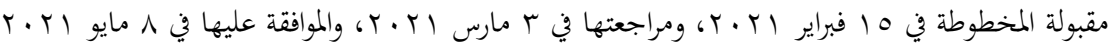

\begin{abstract}
الملخصص
قديف هذا البحث لإستكشاف قيم الوسطية الدينية في الحكمة المحلية لمجتمع باسير ببناجام باسير الشمالية. استخدم

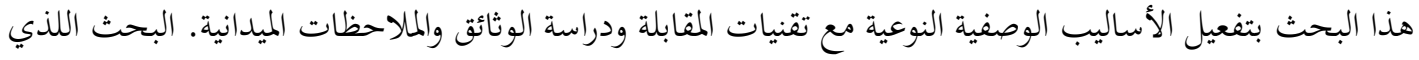

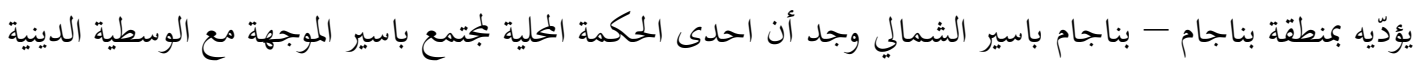

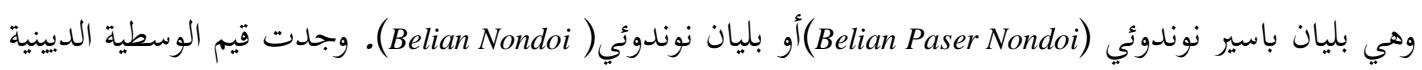

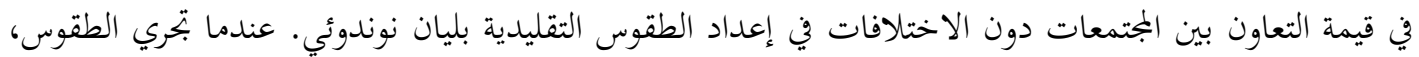
سيجتمع الجمتمع في كوتا ريكان تاتائو للمشاهدة. لديهم نفس الحقوق دون الاختلاف عن بعضهم البعض. مولونج

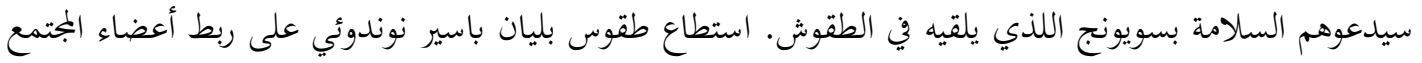
بمعتقدات مختلفة وأعراق مختلفة ولغات وثقافات مختلفة وتصبح ساحة موحدة للناس ببناجام باسير الشمالي. ويمكن بلمئن الحفاظ على طقوس بيليان باسير نوندوي لكي قيم الوسطية الدينية الواردة فيه وتصبح تقليدا في المجتمع، خاصة بالنسبة لجيل الشباب. الكلمات المفتاحية: الوسطية الدينية، التربية، الحكمة المحلية، بليان نوندوي، باسير
\end{abstract}

\begin{abstract}
This research aims to explore the value of religious moderation in the local wisdom of Paser people in Penajam Paser Utara. This research used descriptive qualitative methods with interview techniques, document studies, and field observation. The research conducted in Penajam Subdistrict, Penajam Paser Utara, reveals that one of the local wisdoms of Paser people is oriented towards religious moderation through Belian Nondoi ritual or Belian Paser Nondoi. In practice, the values of religious moderation emerge at the value of cooperation between communities without any difference in the preparation of elian Nondoi rituals, which in the process, the community will gather
\end{abstract}


in Kuta Rekan Tatau to witness that they have the same rights without any difference from each other. All of them will be prayed for their salvation through Soyong which is practiced by Mulung in Belian Nondoi ritual. Belian Nondoi traditional ritual of Paser community can unify the members of different community beliefs, different tribes, languages, and different cultures as well, as a means of unifying the community in Penajam Paser Utara. Thus, the Belian Nondoi ritual needs to be preserved, so that the values of religious moderation contained in it can be maintained and become a tradition in society, especially for the younger generation.

Keywords: religious moderation, education, local wisdom, belian nondoi, paser people

المجتمع من المجتمعات الريفية ببناجام باسير

الشمالي وهو قبيلة باسير. اللغة التي يستخدمها

أعظم سكّان بناجام باسير الشمالي في المحادثة

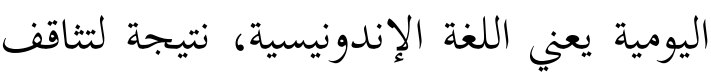

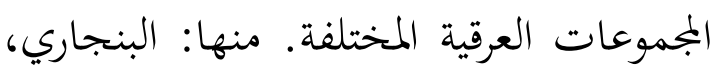
البوقيسي، الجاوي، سوماتري، مالوكوئي، دياكي، وباسيري. وأيضا اللغة الباسيرية يستخدمها في الريف المعظم يسكنه المجتمعات الباسيرية، على الرغم قريبا للإنقراض.

سكان بناجام باسير الشمالي متنوّعون

من حيث الدين. الديانات الرئيسية المعترف بها في إندونيسيا، كلها موجودة في هذه المدينة باستثناء كونجهوتشو. وهي الإسلام والمسيحية

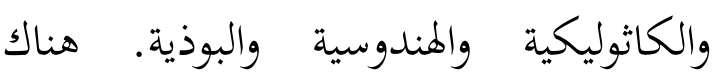

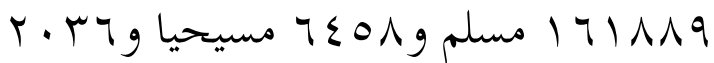
كاثوليكيا و VT هندوسيا وه 1 و بوذيا. BPS دور العبادة Penajam Paser Utara, 2019) بشكل عام في شكل مساجد أو مصلّى، وهناك أيضًا من الكنائس، ولكن لام توجد معابد وأديرة في هذه المنطقة.
سيعيش الجمتمع في منطقة سلاما ووئاما إذا تم تعزيز قيمة الحكمة المحلية. الحكمة المحلية تلخص المعرفة التي طورها الأسلاف للاستجابة

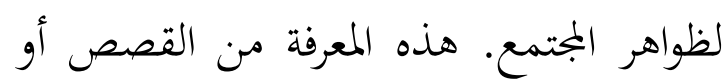
الأساطير أو الأغاني أو الطقوس أو اللوائح

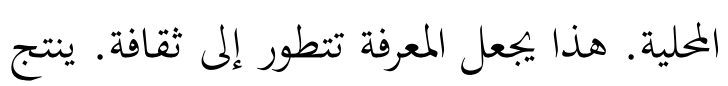
هذا التنوع الثقافي الحكمة المحلية في كل منطقة. تحتوي الحكمة المحلية على حكمة ثقافية محلية. تؤثر الثقافة بشكل مباشر أو غير مباشر على تكوين الحكمة المحلية. (Dokhi et al., 2016) (Meliono, 2011)

التنوع الثقافي الذي يولد الحكمة المحلية هو أيضًا جزء من منطقة بناجام باسير الشمالي. تنقسم منطقة بناجام باسير الشمالي إلى منطقتين، وهما المناطق الساحلية والجبلية بحيث تنقسم الثقافة في هذه المنطقة أيضًا إلى قسمين، وهما الثقافة الساحلية والثقافة الداخلية

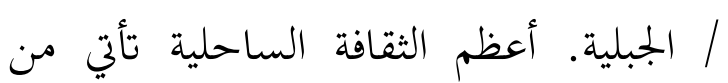
المهاجرين الذين يعيشون على الساحل، وأعظم

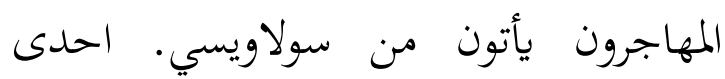


لذلك، لمنع تفكك المجتمع الإندونيسي، من الضروري مواصلة المراقبة من خلال تتبع توجه الاعتدال القائم على الثقافة من خلال تتبع الحكمة المحلية للناس في منطقة

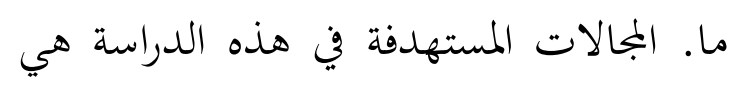
منطقة بناجام باسير الشمالي- كاليمانتان الشرقي مخصصا في المجتمع باسير. تمديف هذا البحث للتعالب: (1) ما هي الحكمة المحلية الموجودة في مجتمع التي تتجه نهو الوسطية

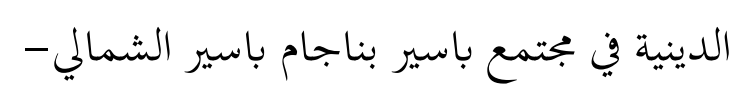
كاليمانتان الشرقي؟ r ) ما هي أشكال قيم الاعتدال الديني الواردة في الحكمة المحلية لبليان أدات باسير نوندوي؟ ب) كيف يمكن تنفيذ استراتيجية تنمية الحكمة المحلية لبليان أدات باسير نوندوي في السياسة؟

رتنو كريستيانتي كانت تقوم ببحث عن

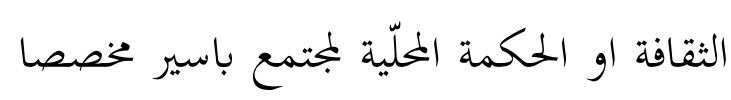
لطقوس بليان باسير نوندوي بموضوع بسويونج

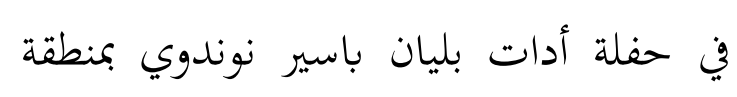
بناجام باسير الشمالي - كاليمانتان الشرقي. يركز هذا البحث على شكل عرض بسويونج

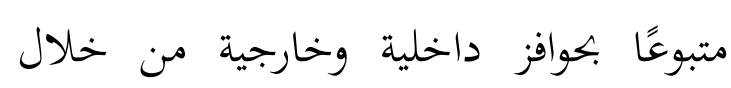
الحضور المشترك لحفلة بليان باسير نوندوي.

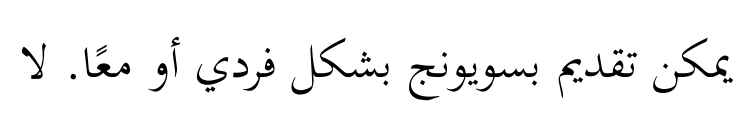

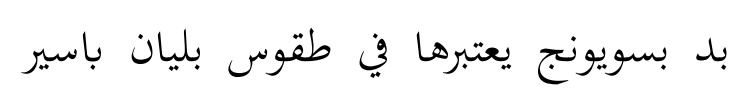

لن يكون تنوع المجتمع صراعًا، طالما أن

الحياة في الممارسة تعطي الأولوية دائمًا لقيم العدالة والتوازن. العدل والتوازن هما مبدئان قيمة الوسطية. الوسطية معروفة ليست فقط في الإسلام، ولكن أيضًا في جميع الأديان. بالإضافة إلى ذلك، البساطة هي فضيلة تشجع على خلق الانسجام الاجتماعي والتوازن في الحياة. سواء كان ذلك في الحياة الشخصية (Agama, 2013, والعائلية والعلاقات المجتمعية.

الوسطية الدينية اللتي تؤدي إلى الانسجام هي أساس الأمة الإندونيسية. بدون

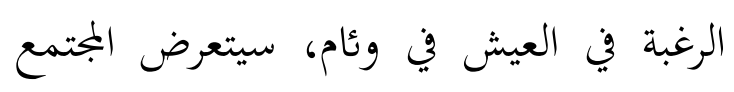

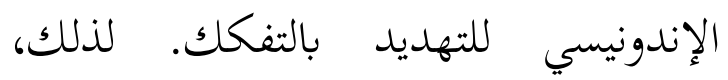
إندونيسيا هي أمة تتكون من مختلف الهويات الاجتماعية والدينية والثقافية. الحين، تصبح ملاحظة الحكمة المحلية للمجتمع إحدى نقاط الدخول لتتبع توجه الوسطية الثقافية، لأهما تحتوي على وصف شامل للذاكرة الجماعية للمجتمع حول الثقافة وحكمة الحياة التي كانت موجودة. تنتقل من جيل إلى جيل. من

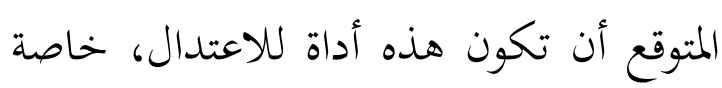
في تطوير وممارسة التعاليم الدينية الأكثر تسامًا. يحتوي على نصائح حول التضامن الاجتماعي القائم على الدين لتجنب النزاعات باسم الدين. (Muslim et al., 2019) 
الأخرى لدعم معلومات المخبرين وتتبع الأدلة بعناية قدر الإمكان. (Yin, 1996, p. 107) أجرت دراسة الوثيقة من خلال تتبع الوثائق

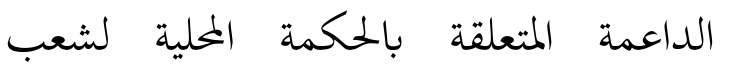

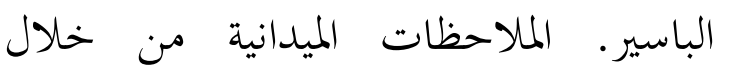
ملاحظات الممارسة الحياتية لمتمع باسير ببناجام باسير الشمالي، خاصة في المناطق غير

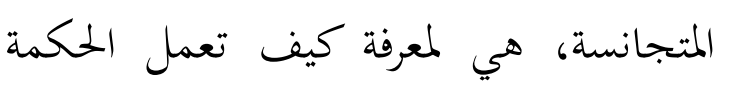
المحلية في المجتمع. موقع البحث في منطقة بمنطقة بناجام باسير الشمالية - كاليمانتان

$$
\text { الشرقية. }
$$

\section{النتيجة والبحث}

الحكمة المحلية المحتملة لبجتمع باسير وليحي

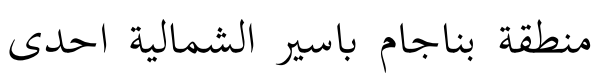

من المنطقة توسعا من منطقة باسير في السنة

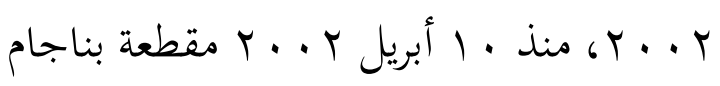
ومقطعة سيباكو. وعاصمتها في مقطعة فناجام. منطقة بناجام باسير الشمالية وسأصبحت منطقة كوتائي كارتانيغارا عاصمتين. أصبحت بناجام باسير الشمالى

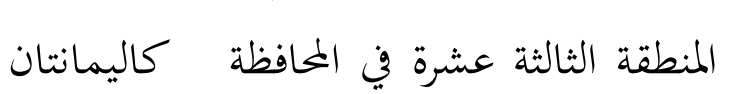
الشرقية. منطقة بناجام باسير الشمالي. تتكون هذه المنطقة من عدة مناطق وهي مقطعة

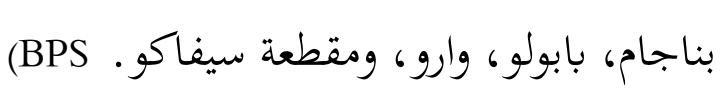

. Penajam Paser Utara, 2019)
نوندوي. العوامل الداخلية التي تشجع على وجود بسويونج هي بتنب الأرواح الشريرة، والدعوة إلى الطقس الجيد لقضاء العطلات، والشفاء، وطلب البركات. العوامل الخارجية فيما يتعلق بوجود بسويونج هو تحسين اقتصاد المنطقة والسياحة وتصبح هوية هذه المنطقة. البحث الآخر عن الوسطية الدينية

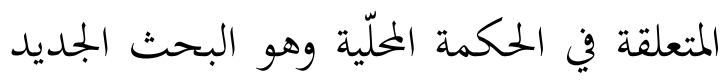
أجراه الباحثو مركز ديني للأبجاث الدينية والإنماء عام 9 ا ـ r. من نتائج البحث، تبين أن التقليد الشفوي يفهم من قبل المجتمع المحلي كان قادرًا على الحفاظ على الانسجام والتناغم بين الأديان الشقيقة والأديان المختلفة لأن التقاليد الشفوية تستخدم لغات إقليمية قادرة على لمس قلوب المتحدثين والمستمعين

\section{منهجية البحث}

يستخدم هذا البحث مناهج البحث الوصفي

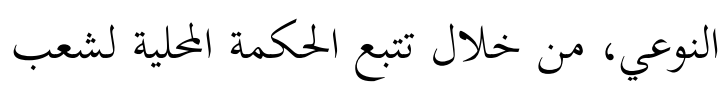
الباسير والتي لا تزال مستدامة والتي ترتبط بالوسطية الدينية. تقنيات جمع البيانات هي مقابلات متعمقة مع المخبرين، ودراسة الوثائق

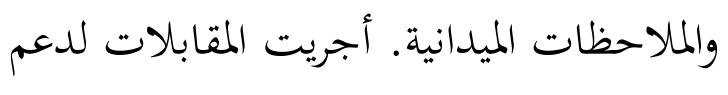
الحقائق، من المخبرين الرئيسيين إلى التغلب على الأخطاء والاعتماد على مصادر الأدلة 
(BPS .Labangka وقرية لابانجكا Darat

Kabupaten Penjam Paser Utara, 2019)

قبيلة باسير هي أقدم قبيلة في جزيرة

بورنيو/كاليمانتان، ويعود أصل بجتمع باسير

إلى فترة داتو نالوو Datu Nalau، اعتقد المجتمع

في ذلك الوقت يسمى إيدن Iden وهو اعتقده

الأجداد. ثم جاء الإسلام والمسيحية بحيث

يلتزم مجتمع باسير عمومًا بالديانتين، واليوم يعتنق بجتمع باسير الإسلام. كما قال سوويس

سانتوسو في المقابلة، مولونج بليان آدات

$$
\text { باسير. }
$$

“Asal muasal Paser sejak zaman Datu Nalau.

Sebelumnya masyarakat Paser tidak menganut agama. Kepercayaan leluhur yaitu "Iden" (Kepercayaan leluhur). Yang dimana cara penguburan, yaitu: Nelungun dan

Kinorarai/ Krarai (berupa pondok kecil tempat mayat, di buat pondok, kelambu di tengah hutan), dan Lungun (terbuat seperti perahu, saat ini seperti peti). Lama kelamaan datanglah Islam dan Kristen, hampir sетиа suku Paser menganut kedua agama tersebut. Suku Paser adalah anak cucu Datu Nalau. Suku Paser adalah suku tertua di Kalimantan. Datu Nalau mempunyai rakyat 8.888 orang.

(المقابلة سوويس سانتوسو، VV سنة،

$$
\text { الأحد rr فبراير r r. (r) }
$$

Datu أصل باسير من عصر داتو نالوو Nalau يتبع دينًا. إيمان الأسلاف هو "إيدن".

حيث طرق الدفن، وهي: Nelungun و Kinorarai / Krarai صغير مكان الجنازة، صنع فندوق، خِذْرِ
قبيلة باسير هي إحدى القبائل التي تقع

أرض أجدادها على طول جزيرة كاليمانتان الجنوبية الشرقية. حاليًا، تنتشر قبيلة باسير في عدة مناطق / مدن بكاليمانتان الشرقية، منها: منطقة باسير، منطقة بناجام باسير الشمالية، منطقة كوتائي كارتانيغارا، منطقة كوتائي الغربية ومدينة باليكبابان. وأيضا بكالمانتان الجنوبية، منها: منطقة كوتا بارو، منطقة تابالونج ومنطقة تانا بومبو. منطقة بناجام باسير الشمالية هي جزء بسيط من منطقة باسير التي يمثل مجتمع باسير جزءًا من السكان. (Mustikawati, 2019) في منطقة بناجام باسير الشمالية، تقع القرى التي يسكنها بجتمع باسير بمقطعة بناجام كما يلي: بتونج/ تونان Petung (Tunan)، نانج Nenang بولومينونج (مووان و سيليمبونج)

6 Buluminung (Muan dan Selimbung) سوتيك Sotek سيفان Sepan' ريكو Riko، شاطئ لانجو Pantai Lango. وتقع بمقطعة سيفاكو، كما يلي: قرية ماريدان Maridan، Binuang بيمالوان Pemaluan، بينووانج وسيموي الثانية Semoi Dua. قرية لانجو بيتش. تشمل مقطعة وارو : قرية سيسولو (جبل باتو) (Sesulu (Gunung Batu) ومقطعة بابولو Babulu الفرعية كما يلي: قرية بابولو دارات 
عبارة عن مزيج من كلمتين، وهما: كلمة belli التي تعني الأنياب وكلمة kellian التي تعني التعافي. كلمة بيليان نفسها هي أنياب شفاء. يمكننا أن نرى هذا من أحد الإكسسوارات التي يرتديها مولونج (زعيم الطقوس بيليان) حيث

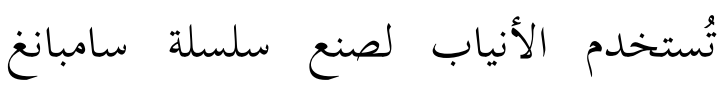
سامبيت sambang sambit. (مقابلة فائدة

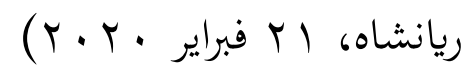

بيليان هو احتفال للاحتفال بلقاء الأرواح والآلة الذين يحتلون الجبال والمحيطات والأنمار والأشجار الخشبية الكبيرة والأحجار الكبيرة وكذلك الأماكن التي تعتبر مقدسة. و من المعلومات التي (Iqbal, 2001, p. 46) حصل عليها من السيد سوويس سانتوسو (مولونج بيليان آدات باسير نوندوي) هو

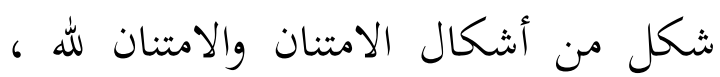
اعتمادًا على المعتقدات الفردية.

تم نقل هذه الطقوس في الأصل إلى

مولونج باسير (ابن ريجانج والو Rijang Walu) في القصص الشعبية الذي تم تناقله من جيل

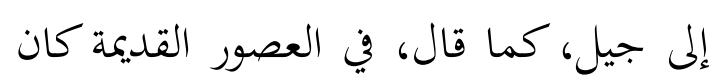
ريجانج والو لديه ثمانية أطفال. يتمتع كل من الأطفال الثمانية بقوى ومزايا خارقة مختلفة.

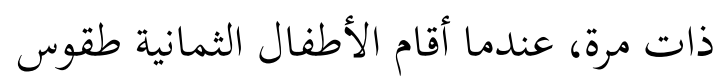
نجارانج الج الرقص) حول المنزل لمدة
في وسط الغابة)، و Lungun (صنع مثل سفينة، حاليًا مثل الصندوق). مع مرور

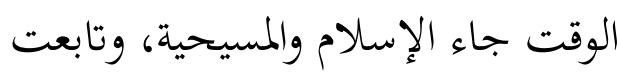
جميع قبائل باسير تقريبًا هاتين الديانتين. قبيلة باسير هي من نسل داتو نالاو. قبيلة باسير هي أقدم قبيلة في في

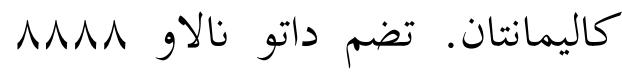
شخصًا" دخول الإسلام في مملكة سادورينجاس

Sadurengas (الاسم السابق لسلطنة باسير) في القرن الخامس عشر بقيادة أبو منصور إندرا جايا من سلطنة ديماك، نقطة الانطلاق لمجتمع

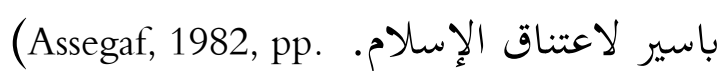

لا تزال ثقافة قبيلة باسير ببناجام باسير

الشمالية مرتبطة أو مرتبطة بالمنطقة الأم، وهي

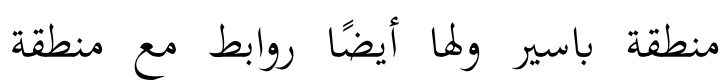
كوتائي كارتانيغارا. من المعروف أن الحكمة المحلية لقبيلة باسير متنوعة للغاية، ولها طابعها الفريد في هذه العملية. من بينها، ما هو حاليًا حدث سنوي هو طقوس بليان آدات باسير نوندوي أو المعروفة باسم نوندوي.

معرفة بليان آدات باسير نوندوي نوندوي هو بيليان على نطاق واسع. تأتي كلمة بيليان نفسها من اللغة الباسيرية وهي 
ثمانية أيام وهم يرتدون غيتانج gitang (سوار Halu Telake) (قبل الانتقال) أصيب بوباء لم

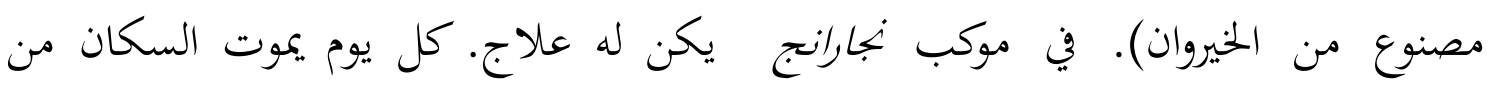
ngarang الثمانية من ريجانج والو في السماء إلى عالم غير التعرض لفجوم طاعون مفاجئ هاجم السكان،

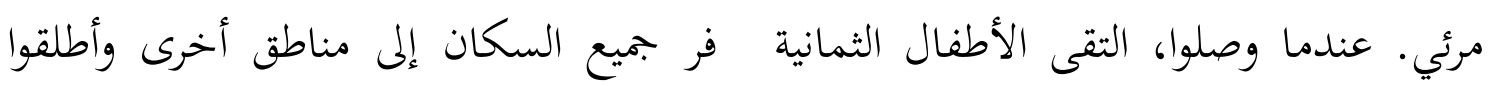

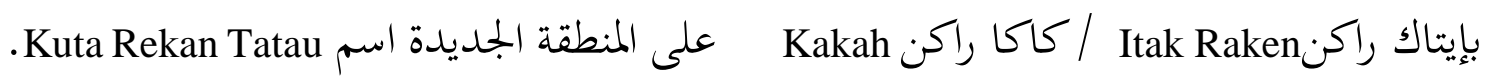
Raken كاكا Kakah Raken ولى شكل وصية ولو يُدعى Kakah Pore Pun Pandai

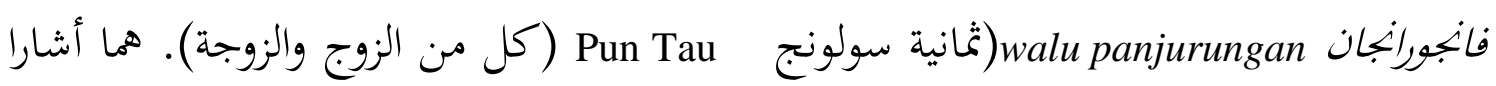
مولونج). لدى عودةم إلى الأرض، وأها إلى Nalau مقابلة طفل Rijang Walu.

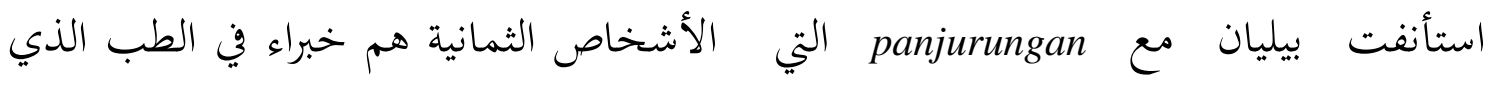

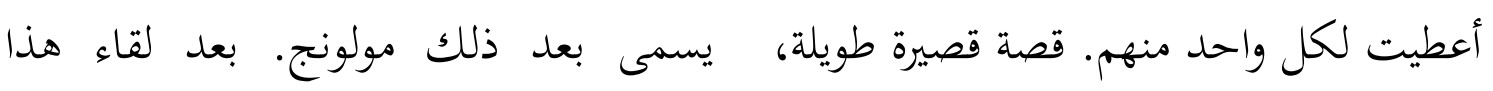

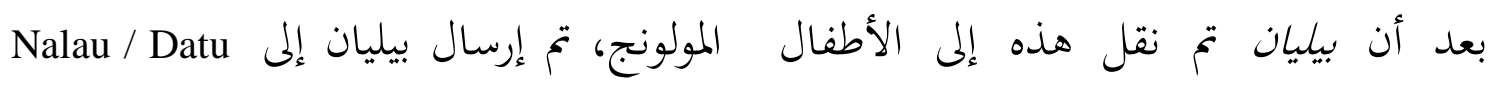
الثمانية، ثم تم تسليمها إلى المولونج (الشخص Nalau وبدأت هذه الطقوس تتطور في حياة الذي قاد الطقوس) المسمى موتاس لولانج الناس ويمتفظ بها بعض الناس بكزم حتى الآن. Mutas Lolang

كما قال سيد سويس سانتوسو (مولونج بيبليان آداة باسير) و سيد يوسّي سمبي سمبان (الزعيم التقليدي لسيبان Sepan) هناك ئسياك

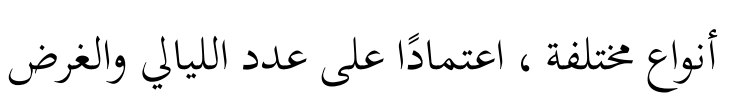
من عملية بيليان. تشمل أنواع بيليان ما يلي:

\section{Belian buat kokat .।}

إها عملية عادية يمكن أن تستمر ليلة

واحدة كحد أقصى. التي تقام عادة بعد حادث حريق.

مولونج) المسمى إيتاك موتاس لولانج ، بعد ذلك كان انتقلت إلى داتو نالاو. (مقابلة بيدا

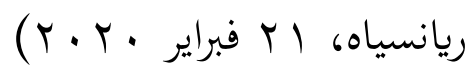
بدأ هذا بيليان في الروافد العليا لنهر تيلاكي (Telake (Utok Telake) وهناك Kuta مستوطنة تسمى كوتا ريكان تاتائو

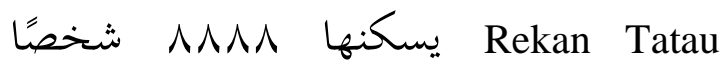
ومستوطنة أخرى تسمى Kuta Lintung Nayu

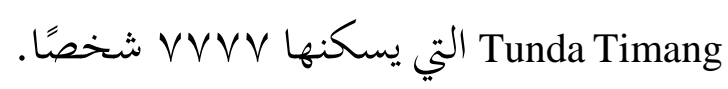
بدءًا من المجتمع المحلي في Kuta Talun Luwai 
تنفيذ هذه الطقوس من قبل المجتمع بهدف تنظيف القرية من الغضب والخطر، ووسائل

الإعلام للعلاج، ودفع النوايا، إلخ.

\section{Belian Nalin Bulan .^}

هو طقوس بليان يمكن إجراؤه لمدة

شهر واحد. يتم تنفيذ هذه الطقوس من قبل

فونجججاوا Punggawa فقط بهدف تنظيف

$$
\text { القرية أو البلد من الغضب . }
$$

Belian Nalin Tahun .9

هو طقوس بليان يمكن إجراؤه لمدة عام

واحد. يتم تنفيذ هذه الطقوس من قبل الملك

فقط، حيث يتم تنفيذ هذا النشاط في

السلطنة. تمدف هذه الطقوس إلى تنظيف

$$
\text { القرية / البلد من الغضب والخطر. }
$$

نوندوي هي أقدم عادات ثقافية في

كاليمانتان. (Panji, 2019). بيليان نوندوي هو

أحد الطقوس التي نشأت في ثقافة سباق

الأسترونيزية (نوسانتارا ملايو). في القرن

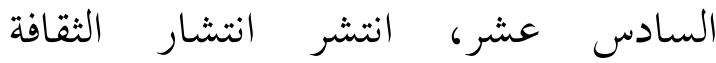

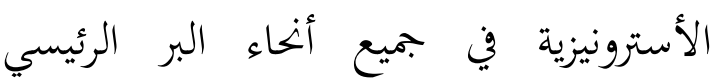

لكاليمانتان عبر طرق الأهمار، وفي هذه الحالة

كانت مرتبطة ارتباطًا وثيقًا بالطقوس الدئار، وفي هذه الحالة

حيث كان الدين الذي يتبناه سكان

كاليمانتان المحليون في ذلك الوقت هو

الروحانية (الإيمان بأرواح الأجداد والنباتات

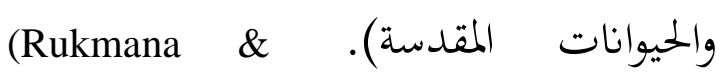

Belian mamo nunggu .r هو طقوس بليان يمكن إجراؤه لمدة أقصاها خمس ليالِ، والغرض منها هو العلاج · لمون

\section{Belian Nyambot Benuo .r}

هو طقوس بليان يمكن إجراؤه لمدة

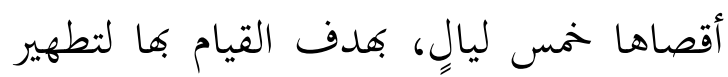
القرية أو البلد من جميع أنواع الغضب والخطر.

Belian Basiaper . .

هو طقوس بليان يمكن إجراؤه لمدة أقصاها خمس ليالٍ. يتم تنفيذ هذه الطقوس بليال من قبل المجتمع بهدف تنظيف القرية أو البلد من جميع أنواع الغضب والخطر. من فئر Belian Bandan . 。

هو طقوس بليان يمكن إجراؤه لمدة

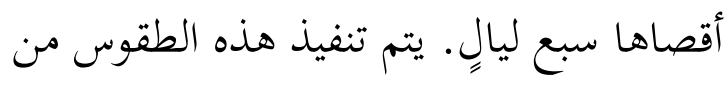
قبل المجتمع بهدف تطهير القرية أو البلد من جميع أنواع الغضب والخطر، والعلاج · تهرئ.

Belian Besawet هو طقوس بليان يمكن إجراؤه لمدة

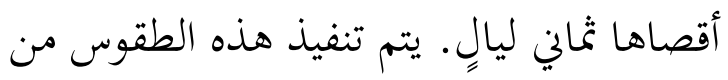

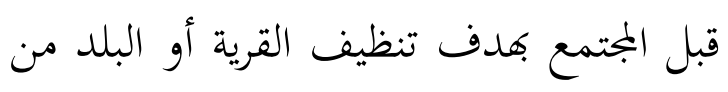
جميع أنواع الغضب والخطر. Belian Nondoi . $\vee$ هو طقوس بليان يمكن إجراؤه لمدة أقصاهاحوالي سبع إلى ستة عشر ليلة. يتم 
Pengkading على وجه التحديد في تلبية احتياجات المولونج Penyendro (r) عند تنفيذ طقوص بيليان). بينيندرو: المتحدث الرسمي. الشخص المسؤول عن نقل غرض عقد بيليان.

\section{موكب تنفيذ طقوس بيليان نوندوي}

في موكب موكب تنفيذ طقوس بيليان نوندوي

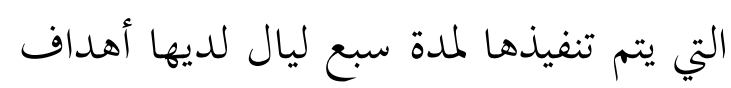

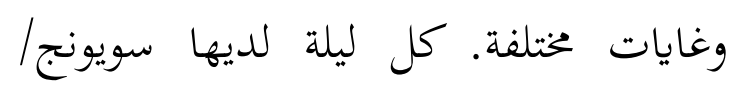
الدعاء مختلفة يقرئها مولونج. الأشخاص المتورطون فيه هم مولونج وفينجنجادنج والأشخاص الذين يريدون العلاج أو المساعدة وقبيلة باسير. تنفيذ بيسويونج بهدف: كوسيلة

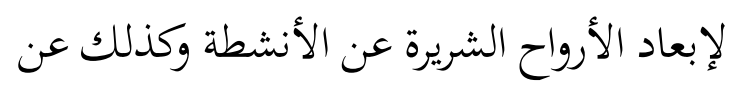

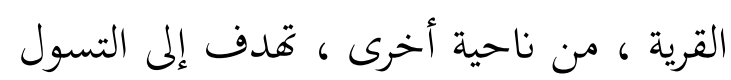

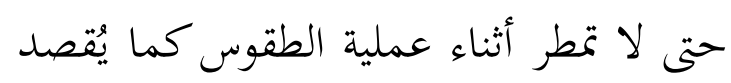

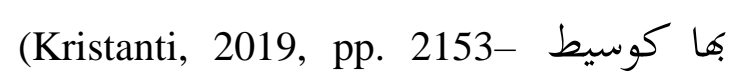

تطبيق بيليان حيث يمكن أن يصاحب

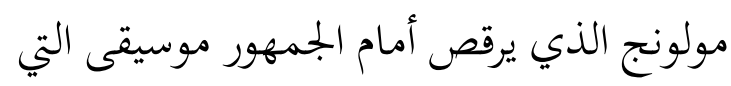
تصاحب إيقاع القدمين. ويتأرجح في اليدين، ويميط جوز الهند أو بورقة سانجامبون بلغة باسير. بعد رقص، جلس مولونج ويقرأ بيسويونج. كان هناك تعبير على وجهه كما لو كان يتحدث إلى بعض الناس. لقد حان

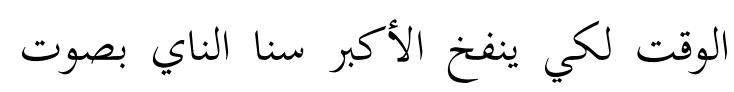

هamdani, n.d., p. 77) هي المعتقد يؤمن بأرواح الأسلاف أو المرحاليه

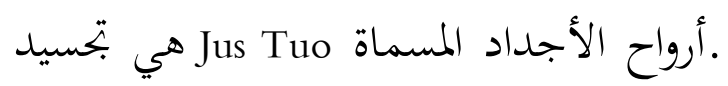
للأسلاف الذينماتوا، وتحولوا إلى تماسيح ونمور وتنانين والثعابين وما إلى ذلك. Ayub, 2010, هـ هذا هو المرجع لمجتمع قبيلة باسير الذين هم مسلمون بالمناسبة، مما يجعل هذه الطقوس وسيلة لاستكشاف الفنون والثقافة بمنطقة

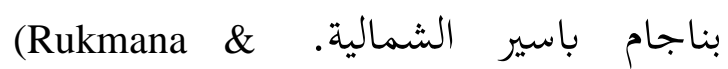
Hamdani, n.d., p. 77) أما المعدات المستخدمة في بيليان، وهي - - - - -

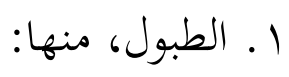

Tino .a Gendeng .b Lumba .c "Kenong/ Kalongtangen .d Agong .e r Gitang (إكسسورات لمولونج في شكل أساور) (قلادة Sambang Sambit.r مصنوعة من الأنياب) ـ . Lawung Utok (عمامة الرأس) ๑ . .

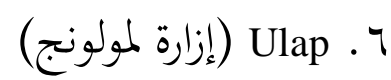
Pendeng/ siyek .V فناني أداء الطقوس البيضاء، وهم: (1) مولونج mulung (زعيم طقوس)، (r) 
Siye derang mamuruko, siye te wase ampe

يتم نقل هذا الهدف إلى تسعة

الأوصياء. تظهر التسعة اسم الأولياء، ووي

المقطع التاسع تصل الدعاء. وهي تمف إلى

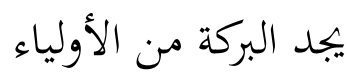

بعد ذلك، استمر سويونج :

Engket sindai buat tabe

Duo derang buat tabe

Tolu derang buat tabe

Opat derang buat tabe

Limo derang buat tabe

Onom derang buat tabe

Turu derang buat tabe

Walu derang buat tabe

هدفه هو طلب الإذن ثماني مرات،

طلب الإذن للسماء والأرض:

) Tabe' langit tombonuto

لوسمحت السماء فوق الرأس)

)tabe' tanah imbat botis

$$
\text { لوسمحت الأرض تحت قدمين) }
$$

في وقت تنفيذ الطقوس، كلهم

مشغولون بأعذار بلغة باسير Sabi Sepa،

Soyong Simong"

مé

ץ. الليلة الثانية حتى الليلة الرابعة

malom ngantung الليلة الثانية هي

ngalom bayung

الأولى، بترديد سويونج بشكل مختلف .

ب. - م. الليلة الخامسة
طويل يشير إلى بدء بيليان. برقصته المقدسة،

يردد مولونج تعويذة أو مرشدًا وصخورًا وجبالًا

وأهارًا وكهوفًا لاستدعاء الآلهة وأرواح الحكام

أو الأوصياء في الكون في الهواء والبحر والأرض

التي تحتل أشجارًا كبيرة وخشبية كبيرة. طلب

المساعدة في علاج مرض يعاني منه شخص أو

قرية يصابها الوباء. (Iqbal, 2001, pp. 47-48)

من المعلومات التي حصل عليها من

السيد سوويس سانتوسو والسيد يوسي، وذكرا

أن موكب في طقوس بيليان نوندوي لديه

إجراءات تنفيذ مختلف كل ليلة. مراحل تنفيذ

طقوس بيليان نوندوي على النحو التالي:

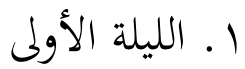

الليلة الأولى وهي nindu (ليلة الافتتاح)

حيث تنفيذ الطقوس عادةً بدءًا من الساعة

الثامنة ليلا حتيّ الساعة الخامسة صباحا. في

الليلة الأولى من سويونج التي غناها مولونج

التي تحتوي علىsabi sebak سابي سيباك.

سويونج تستخدم في لغة باسير "الدقيقة" التي

لا يمكن فهمها إلا من قبل أشخاص معينين.

واحدا من أصوات سويونج كانت تغنى في

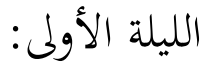

Engket sindai mamoruko

Duo derang mamoruko

Tolu derang mamoruko

Opat derang mamoruko

Limo derang mamoruko

Onom derang mamoruko

Turu derang mamoruko

Walu derang mamoruko 
الأدوات التي أعدها مساعدة مولونج

$$
\text { penggading تسمى }
$$

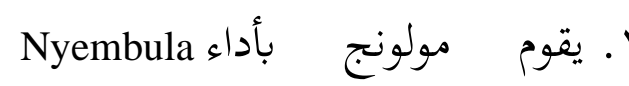

Nongkorong Belian

$$
\text { هذه العملية، يردد المولونج تعويذة تسمى }
$$

سويونج والتي تستخدم لغة باسير Banau TمTatau وين هذا الموكب زعيم مولونج يستحم مولونج الآخر في مكان واحد، وعادة أمام البوابة الرئيسية التي يجري فيها النشاط المكان. يستحم القائد أثناء تلاوة المانترا مصحوبة بالموسيقى. في هذا الموكب يتم خلط الماء الأخير بالزهور. الغرض من عملية الاستحمام هذه هو أن يقود مولونج حفل تطهير للجسد والروح على أمل أن تتحقق كل رغباته وآماله. عادة ما يتم تنفيذ وقت الاستحمام هذا في منتصف الليل أو في أوقات معينة وفقًا لتوجيهات القيادة.
الليلة الخامسة أو malom nyabi وهي ليلة وداع الأشياء غير المرئية. في الليلة الخامسة تتميز بقرع طبلة أجونج

.(agong) ؟ ـ الليلة السادسة

والتي تسمى نيوندوك nyundok وتعني ليلة الإغلاق والتشطيب والتغذية. في الليلة السادسة استمرت في الليلة السابعة. هـ الليلة السابعة

الليلة السابعة أو nembot ruwo هي عملية إعادة الروح إلى مكاها الأصلي. إجراءات تنفيذ الطقوس من البيانات التي جمعها من قبل السيد بيداه ريانسياه (رئيس معهد باسير للدفاع العريف (LPAP) بيناجام باسير الشمالية)، على النحو التالي:

$$
\text { - }
$$

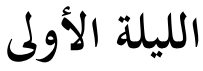

ا . أداء رقصة Manang Juwataمثل اختبار ب. مسانج غيتانج Masang gitang مهي علامة على بلدء الأنشطة، كشكل من افتتاح طقوس بيليان في هذا النشاط أشكال شراء التقارير إلى الأرواح الأجداد حتى يعرف Timang ،Nayu ‘ Uwok ، الأنشطة وعدم التدخل أثناء المرور نشاط
الافتتاحي على جميع الآلات الموسيقية والأجهزة الأخرى مثل kebuong Bungo وبيض الدجاج الحر والشموع والعسل والأرز والعملات المعدنية وغيرها. 
Nyerah kepit pangonjoran gelar yo bawe ratu jengak

Nyerah sengjang siru sagi

Nyerah taruk iyu engket silu/biowo kongkom kayang (تسليم زعنفة القرش/ حاكم<smiles>CC[AlH]</smiles>

Nyerah sarung pakang engket mulang

Nyerah ulau ngket nalau

Nyerah serawu walu engket nayu

Nyerah daun kombat engket pujat

تسليم بجموعة من الآلات الموسيقية

مثل: lumba, gendeng, tung, tino, agong, tembeuen, tangkanong, gambang loyang Nyerah seperangkat alat musik seperti lumba, gendeng, tung, tino,

Nyerah bungo torang olo loak beras pirak

Nyerah olo sinaliling Leyai Lamgit penagar bintang /pelangi/ Juwata محاطًا بأقواس قزح ، وسماء مسيجة<smiles>[Al]=[As]</smiles>

Nyerah toli kasai danum lampuk

bowoi

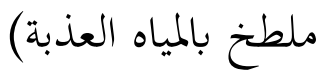

7. رحب مولونج سيراح سيرون من رجل التوصيل السيرون الذي أعطاها.

V . رجل التوصيل السيرون ألقاها عاديا ماذا تسلم مولونج إلى فينجادينج من
ع. تيبونج تاوار Tipong Tawar

، sengiang olo سينجيانج أولو

سينجيانج بولان sengiang bulan

لتكون سعيدًا، هادنًا، يصبح القلب

السيئ جيدًا "lio doli kati lementai

Bulan "

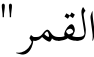

ه . Tukang serah seron (ناقل النوايا) حول

نوايا الناس وهو يرافقه تسليم الأدوات

بيليان مولونج. وصف نوايا الحشد ثم

يرافقه تسليم الأدوات هو كما يلي:

Nyerah ruang walu

Nyerah ruang opat

Nyerah panja war bulau

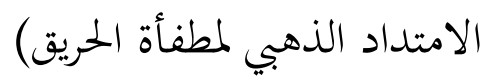

Nyerah selaman lawai

تطريز الخيوط)

Nyerah potan puti tinangkorong

$$
\text { (تسليم أعواد عيدان) }
$$

Nyerah ibus

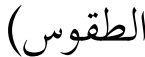

Nyerah tolang jamban onam buti<smiles>[AlH2]=[AsH2]</smiles>

Nyerah solong panjurungan (تسليم أطراف لانجونج / المكان الذي تستخدم فيه الزيوت (التعويذة ) 
الأنشطة السلسة من بيليان ليتم

$$
\text { A. أعاد فينجادينج إلى رجل التوصيل السيرون أي نوايا تم تقديمها / نقلها الليلة الرابعة }
$$

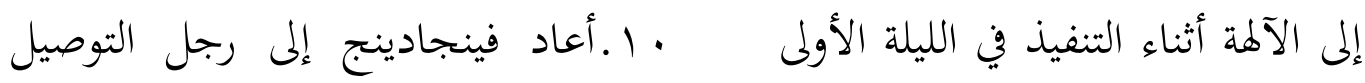
ونقل نقص المعدات أو معدات الطقوس التي يجب إكمالها من أجل الآلة أثناء التنفيذ في الليلة الرابعة، ونقل الأنشطة السلسة من بيليان ليتم لقص المعدات أو معدات الطقوس التي يجب إكمالها من أجل الأنشطة السلسة تنفيذها.

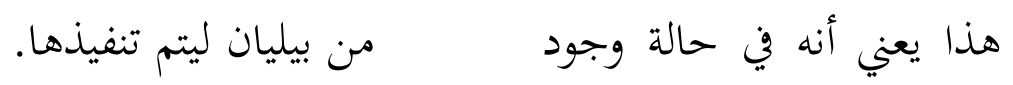

نقص في المعدات / المعدات التي الليلة الخامسة

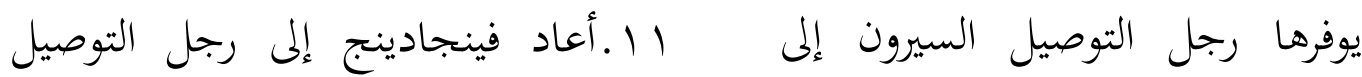

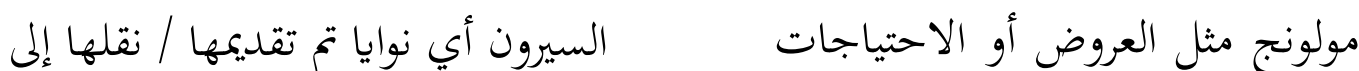

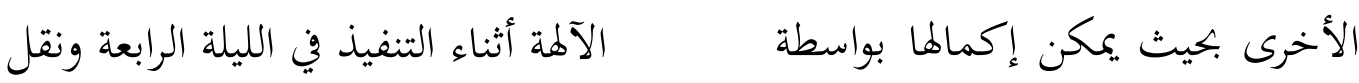
رجل التوصيل السيرون من أجل حسن نقص المعدات أو معدات الطقوس التي

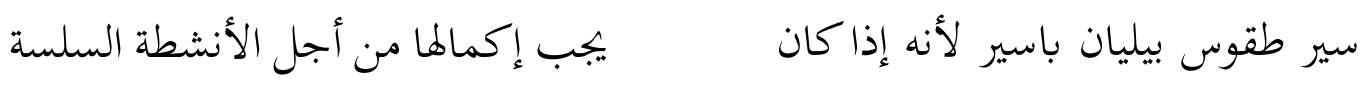
من بيليان ليتم تنفيذها. لا يزال هناك النقص عادة ما يتردد مولونج في تنفيذ طقوس بيليان باسير

في الليلة الخامسة مخصصة للأشخاص الذين لديهم إرث من أي نوع (كريس، تومباك، مرجل، صابر، سادوب، توتنهام، إلخ) ويريدون تنقية هذه الموروثات، يمكن أن تعطي الإرث ليتم غسلها إلى مولونج الذي يقود.

$$
\text { خوفًا من الآلهة. }
$$

الليلة الثالثة

9 . أعاد فينجادينج إلى رجل التوصيل

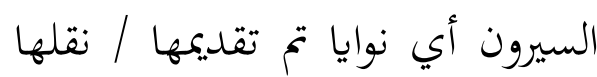
إلى الآلمة أثناء التنفيذ في الليلة الثانية ونقل نقص المعدات أو معدات

\section{الطقوس التي يجب إكمالها من أجل الليلة السادسة}

r ا.أعاد فينجادينج إلى رجل التوصيل

السيرون أي نوايا تم تقديمها / نقلها إلى لى لئل 
حسّن صوتك لتقرأ أو تغني أو

تتحدث في الأماكن العامة.

الأطفال مطيع تتحسن

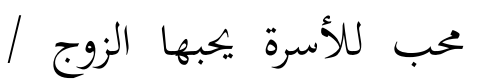

الزوجة ويجبها كثير من الناس.

خ!
الآلهة أثناء التنفيذ في الليلة الخامسة

ونقل نقص المعدات أو معدات

الطقوس التي يجب إكمالها من أجل

الأنشطة السلسة من بيليان ليتم

تنفيذها.

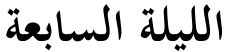

ه Empit nauk (ngambur danum). 1 T

حدث لغسل المياه / نثر المياه من أجل

rا.أعاد فينجادينج إلى رجل التوصيل

السلامة ولكي يكون القلب سعيدًا

ومسالمان

Ngundus tuo.1 V

الاستحمام لقادة المجتمع، والزعماء

التقليديين، و والمسؤولين الحكوميين،

بحيث لا يكون هناك أي تدخل من

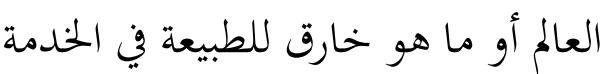

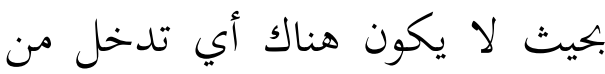

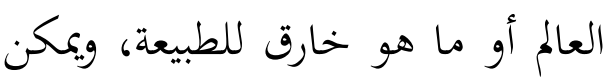

أن يقرر الأمر بإنصاف قدر الإمكان

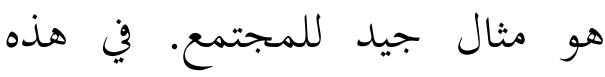

الطقوس، يجب على الشخصيات

التقليدية التي سيتم الاستحمام بها

إعداد دجاجة بيضاء للاستحمام

وكرسي مصنوع من الخيزران الأصفر / لحمنهاء

الأخضر.

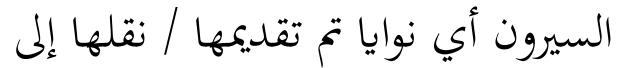

الآلمة أثناء التنفيذ في الليلة السادسة

ونقل نقص المعدات أو معدات

الطقوس التي يجب إكمالها من أجل

الأنشطة السلسة من بيليان ليتم

$$
\text { تنفيذها. }
$$

الإختتام

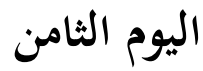

ـ Namburoso 1 نامبروسو يبدأ في الصباح

حوالي الساعة السادسة صباحًا،

والهدف إلى استدعاء الأرواح /

المخلوقات غير المرئية، لإظهار جميع

العناصر التي سلمها مولونج.

Nyukit jenis-jenis lenga pangkase . 10

وهي طقوس حب الزيت الممنوح ل:

الأطفال الذين هم أقل طلاقة

في الحديث من أجل أن يكون

يجيد التحدث 
1 1. Nulakjakit/mendiwajakit/ هذا هو توراجائي، مانداري، باجاؤوي، مادورائي، حفل تتويج لطقوس بيليان باسير فلوريسي، لومبوك، وباتاك وباسيري وغيرها. لأن منطقة بناجام باسير الشمالية منطقة غير نوندوي

متجانسة. نظرًا لأن بناجام باسير الشمالية يسكنها بجموعات عرقية مختلفة غير متجانسة مع تنوع ثقافي، بالإضافة إلى ثقافة باسير التي تعد الثقافة العرقية الأصلية، هناك أيضًا ثقافات مثقفة مع مختلف الثقافات الأخرى، بما في ذلك ثثقافة البوقيسي- الباسيري، ثقافة الجاوي- الباسيري، البانجاري- الباسيري، دياك- باسير وهلم جرا. على الرغم من وجود تنوع ثقافي، إلا أن هذا لا يسبب الانقسام أو الصراع. في الواقع، يصبح غراء موحد لشعب بناجام باسير الشمالية. Dinas Kebudayaan) dan Pariwisata Kabupaten Penajam Paser Utara, 2018, p. 1)

قيمة الوسطية الدينية تظهر في حياهم

اليومية، حيث يعيشون بسلام حتى في منطقتهم متعددة الثقافات، حيث يوجد في سيبان (Sepan) ليست مأهولة فقط بقبائل باسير، بل تسكنها أيضًا قبائل أخرى. كذلك الجالية بالإضافة إلى الإسامج، والبعض الآخر مسيحيون وكاثوليك، وفي هذه الحالة يمكننا أن نرى كنيسة على الطريق المؤدي إلى مقر بيت

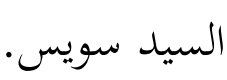

لارونج جاكيت هو الطقوس الأخيرة لموكب طقوس الشراء العرفية في باسير، وهي طقوس انجراف طوف خشبي كبير برأس التمساح وزخارف الذيل التي تم تزيينها بزخارف شجرة نيباه جانور، وفيها يتم وضع بعض وجبات الباسر التقليدية الخفيفة والطعام كرمز للامتنان والرجاء لله سبحانه وتعالى على الحظ والبركات والأمان والسالام. كما يتم ترتيب الطوافات المستخدمة أيضًا وفقًا لعدد المرات التي نقيم فيها طقوسًا نوندوي. في هذا الموكب، سيدعو مولونج الذي يقود الطقوس الآلهة وينقل للآلهة أن طقوس بيليان قد انتهت ويريد تقديم القرابين كشكر وامتنان للاحتفاظ به خلال هذه الطقوس حتى لا توجد أشياء غير مرغوب فيها مثل يحدث. قيم الوسطية الدينية والتربية في طقوس بيليان آداة باسير نوندوي

قام بمجتمع باسير الحياة اليومية ببناجام باسير الشمالية جنبًا إلى جنب مع مختلف القبائل، بما في ذلك: البوقيسى، البنجاري، الجاوي، سوماتري، مالوكوئي، دياكي، 
وصلنا إلى منزل والدي السيد سوويس وما كان الغرض من مجيئنا إلى هناك. ثم شرح الرئيس التقليدي ليسيفان السيد Yossi Samban أيضًا

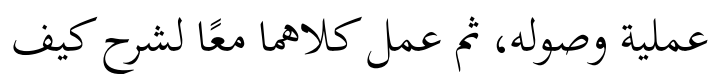
عدم وجود نوندوي هو حقًا. إن عملية إعادة سرد الأحداث التي وقعت قبل لقائهم بأكبر قدر ممكن من التفاصيل هي مظهر من مظاهر

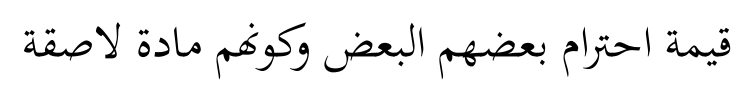

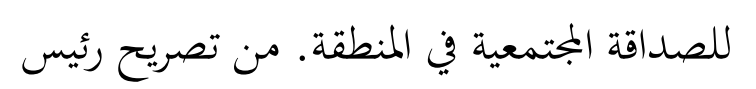
مؤسسة باسير بمنطقة بيناجام باسير الشمالية،

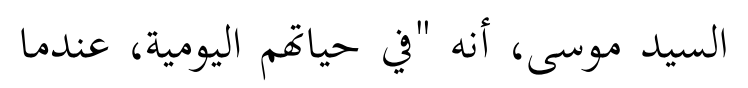
يجتمعون، سيخبرون التسلسل الزمني للأحداث حتى يجتمعوا، على سبيل المثال في طريقهم

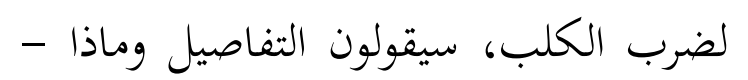

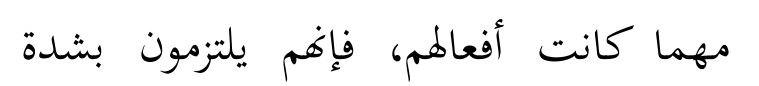
بالأخلاق." مهال

من ناحية أخرى، من المعلومات التي يجصل عليها من السيد موسى، على الرغم من أن مجتمع باسير في سيبان Sepan يغلب عليه

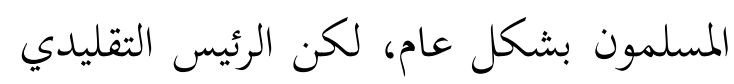
ليسيفان السيد Yossi Samban هو قس. وما زالوا يقدرون ويحترمون رأس العادات على الرغم

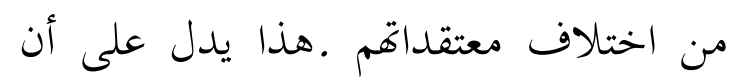
مناخ الوسطية الدينية في حياة مجتمع باسير يظل مستدامًا ويمتزج في الحياة اليومية.
المجتمعات الذين يعيشون في الريف هم

أشخاص يسعدهم تقديم المساعدة أو المساعدة لأي شخص يحتاج إلى المساعدة دون الحاجة إلى معرفة من يمتاج إلى المساعدة. بالإضافة إلى ذلك، فإن بجتمع باسير هو بجتمع ودود دائمًا في الجمعيات ويعطي الأولوية للتداول والإجماع في اتخاذ القرارات المختلفة. لن يتخذ المواطنون قرارًا أحادي الجانب يعطي الأولوية فقط لمجموعات / مجموعات معينة. يجب حل المشاكل المختلفة من خلال إعطاء الأولوية للمصالح المشتركة من خلال التوافق. Arifin) et al., 2010, p. 43)

يتضح موقف الاحترام المتبادل لبعضهم البعض والأهمية الكبيرة للأخلاق في حياتم اليومية. حدث هذا، عندما أجرى الباحث مقابلة مع السيد سويس سانتوسو تمخ في منتصف حديثنا، حضر الرئيس التقليدي ليسيبان (بعد أن تم الاتصال به سابقًا عبر الهاتف) وطلب السيد سوويس سانتوسو الإذن

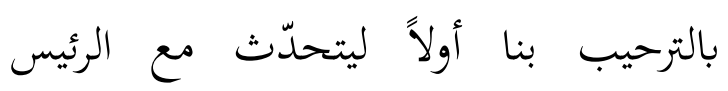

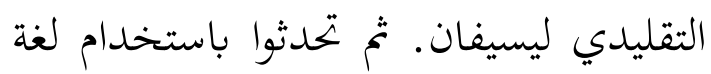
باسير حيث في جوهر محادثتهم، شرح السيد

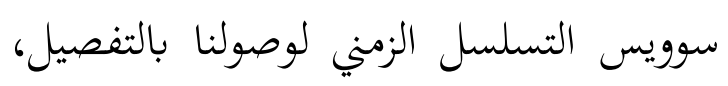
بدءًا من وقت رئيس مؤسسة باسير للسكان

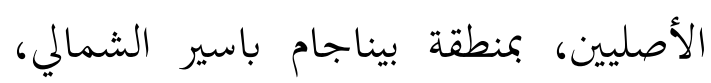
اتصل السيد موسى بالسيد سوويس حتى لمعيل 
لأنه في الواقع، من وجهة نظر الإسلام، ولغات خختلفة وما إلى ذلك، سيتم دعوقم

$$
\text { كل البشر إخوة على الرغم من اختلاف ل جميعًا. }
$$

في موكب طقوس بيليان باسير

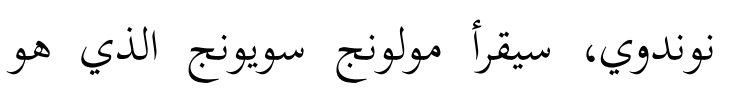
جوهر طقوس بيليان باسير نوندوي.

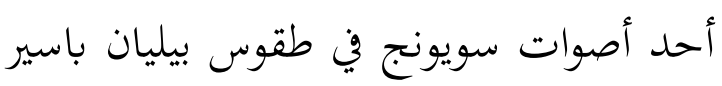

$$
\text { نوندوي هو: }
$$

Walau ulun bao mak

Walau ulun bao lain

Aso jakit erai siret

Dalai erai urai

Aso pinang erai tumpa

Kelapa erai langgar

Nang ene sala Otis

Nang ene sala omoi

من المعلومات التي تم الحصول عليها من السيد سوويس سانتوسو المعنى من سويونج متماثلون هو السماح له أن يكون أشخاصًا

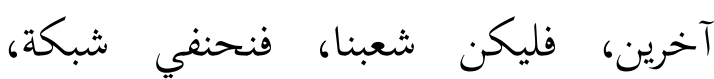
متحدون في قارب/ إطار واحد، في خط فينائن متناغم). جوز التنبول وجوز الهند متشابهان، حيث تتشابه نماذج الفاكهة والزهور. المعنى: رغم اختلاف العادات إلا أن الهدف واحد وهو أن نشكر الله (الآباء أولاً إلى الأجداد). لاحظوا جوز التببول، فهو يتألف من مجموعة أله

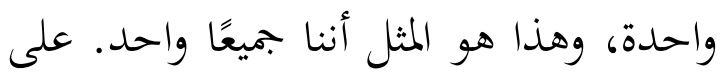

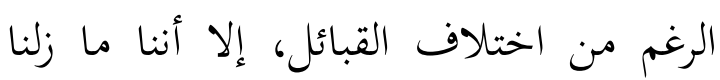
واحدًا. هذا هو هذا التنوع الفردي. قبل احنب تشغيل مختلفة لكنها لا تزال واحدة، كان
القبائل أو الديانات. على الرغم من أن أهل عد وثمود ومدين عارضوا رسلهم، إلا أن القرآن

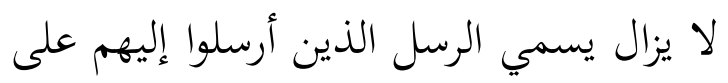
أهم إخواهم، معتقدين أفم بشر) (اقرأ القرآن

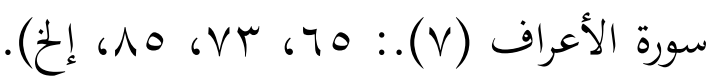
لذلك فإن الصيغة التي قدمتها سيدنا علي رضي دقيقة للغاية: "من تقابله فهو أخوك أو

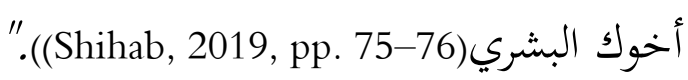
لا يزال العثور على قيم الوسطية في طقوس بيليان نوندوي التي تنفيذها على مدى

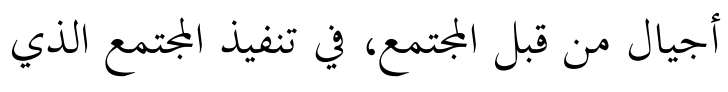
يعقد الطقوس سوف يطلع ويدعو كل عناصر المجتمع دون تمييز بعضها البعض. ليعل

"لا، الجميع مدعوون، حتى من القبائل

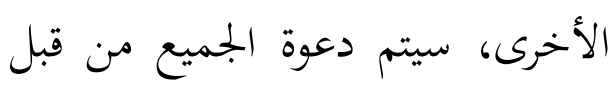
أولئك الذين يمتلكون الشراء أجاب

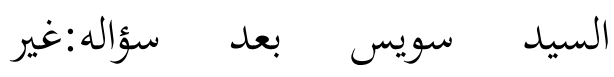
المصقول".

قبل أن يقوم شخص ما بشراء عقار غير تجاري ،سواء كان ذلك لغرض العلاج، لدفع نذر، يجب عليه أولاً الإعلان ثم دعوة جميع الأشخاص دون تمييز ضد بعضهم البعض. على الرغم من أفم من قبائل وديانات 
نوندوي كل عام بالقرب من غهاية العام من

قبل جتمع قبيلة باسير في مناطق معينة لصلة الرحيم مع القبائل الأخرى الموجودة والتي اختلطت بمنطقة بيناجام باسير الشمالية. ومع الشع الشعابل ذلك، فإن مشاركة الحكومة في هذه الأنشطة

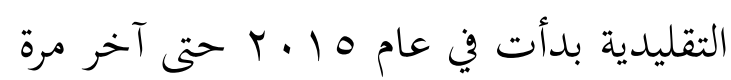

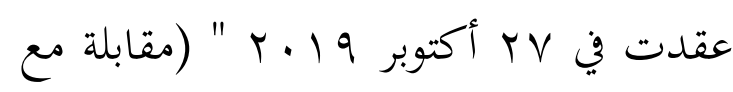

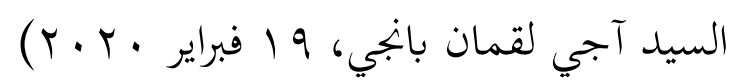

من أجل الحفاظ على الثقافة، تم حماية

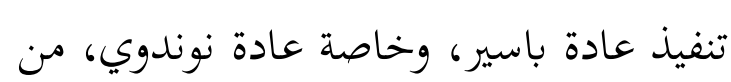
قبل الحكومة في اللائحة الإقليمية بمنطقة

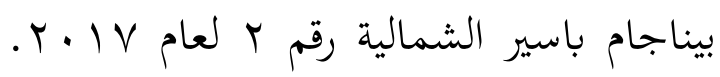

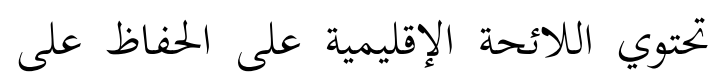
باسير ومايتها العرفية المدرجة في الفصل الثاني المادة ع الفقرة r د. وتنص الفقرة ا من المادة

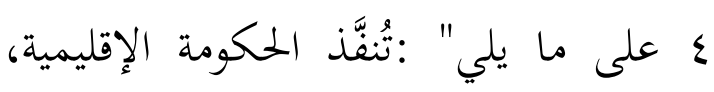

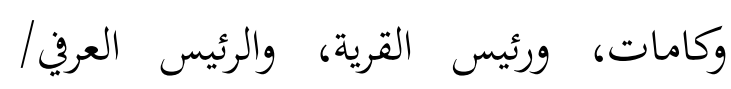

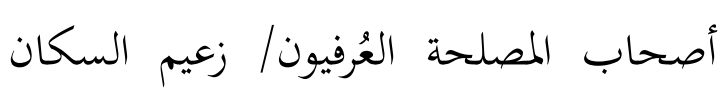

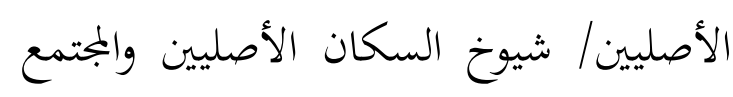

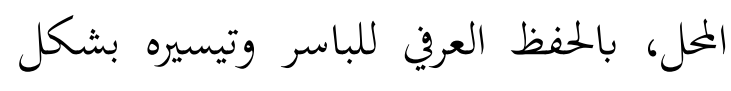

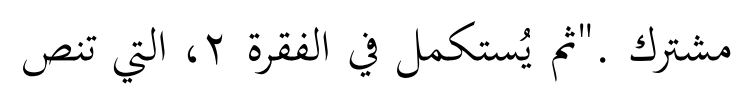
على" :يتم إجراء الحفظ على النحو المشار إليه

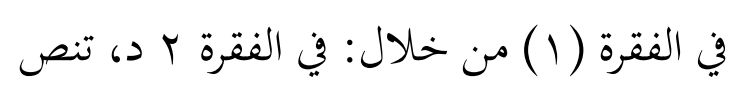
الفقرة على ": تنظيم النشاط السنوي لعرف غير

المصحح."
مجتمع باسير يعرف بالفعل ما هو موجود في هذا سويونج.

في هذا سويونج يعني جميع البشر من

الأطفال إلى البالغين، ذكورًا وإناثًا، حتى لو لو

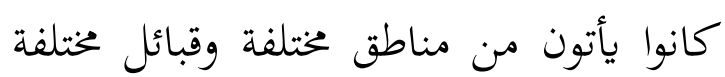
وديانات خختلفة وثقافات يختلفة، لكنهم يظلون واحدًا الجميع من أجل سلامتهم. من خلال سويونج. البشر بشكل عام في سويونج تشبيه بشجرة التنبول، التي لن تكون ثمارها بالتأكيد كبيرة أو صغيرة، لكنهم متحدون في مجموعة واحدة.

القيم التربوية للوسطية الدينية الواردة في

طقوس بيليان نوندوي مثل التعاون، وقبول الأشخاص ذوي الخلفيات والهويات المختلفة، هي قيم يجب رعايتها وترديدها، خاصة بالنسبة لجيل الشباب.

\section{نوندوي في السياق المعاصر}

طقوس بيليان نوندوي هي أقدم حكمة محلية لشعب كاليمانتان. تحققت رغبة قبيلة باسير بمنطقة بيناجام باسير الشمالية في

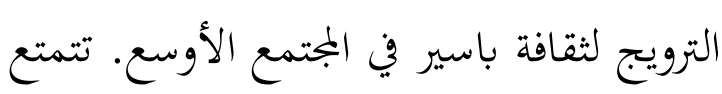

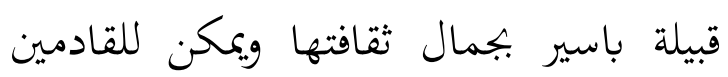
الجدد أيضًا بحربة جميع جوانب قبيلة باسير من فئن خلال هذا العيد التقليدي" .تم تنفيذ عادة 
نوندوي هي طقوس سنوية تقيمها الحكومة سيتيو (رئيس قسم التراث الثقافي والثقافي)،

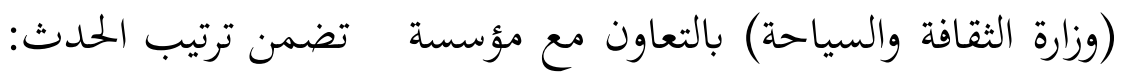

افتتاح حفلة طقوس بيليان باسير نوندوي ظهرًا، حيث سيتم في هذا الافتتاح عرض فني ثقافيًا، ستؤدي جميع المجموعات

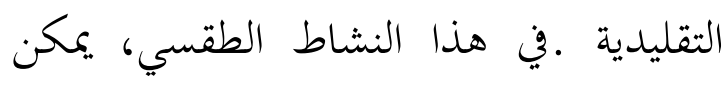

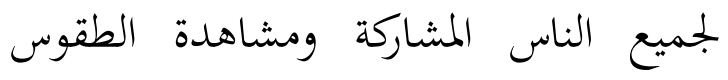
مباشرة. هذه الطقوس مفتوحة للجمهور. العرقية في بيناجام باسير الشمالية رقصات من المعلومات التي حصل عليها من

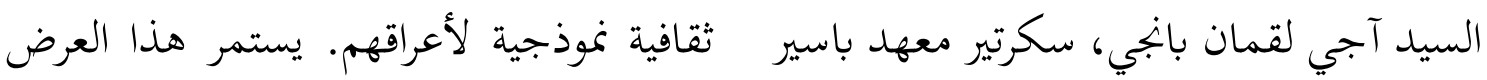

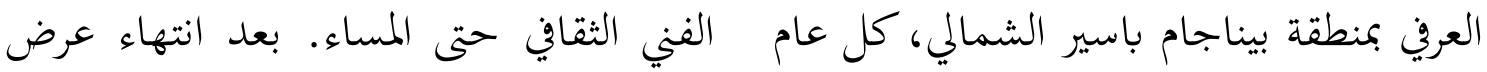

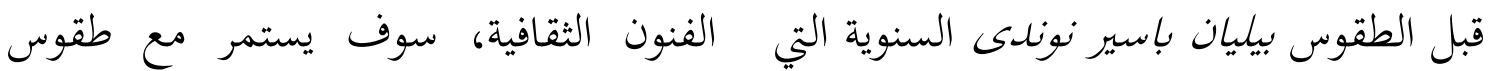
قام بمنطقة بيناجام باسير الشمالية، سيعمل بيليان التقليدية حتى الفجر بقيادة مولونج. في هذا النشاط، سيتم عرض المعارض والشركات الصغيرة والمتوسطة، وعروض الفنون والثقافة، وronggeng benuo taka، والتوعية

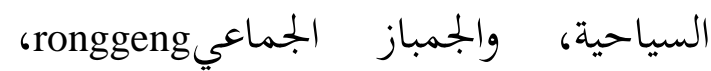
ومسابقات الكالام، ومسابقات التهات التلوين، ومهرجانات الطهي والمسابقات الرياضية التقليدية النموذجية بجموعة باسر العرقية. جميع

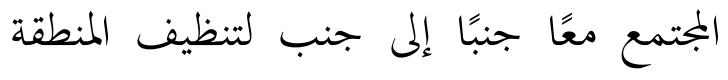
المحيطة بالمنزل التقليدي .يكون المنزل التقليدي أو اللامين هو المكان الذي طقوس تقام فيه نوندوي .المنزل التقليدي بمنطقة بيناجام باسير الشمالية يسمي . Kuta Rekan Tatau" في قرية نيبا نيبالNipa-Nipa ، مقطعة بينجام، بمنطقة بيناجام باسير الشمالية. الأنشطة والمسابقات مفتوحة للجمهور ، ولكل من يرغب في المشاركة نفس الفرصة في هذه الأنشطة.

حفلة بيليان نوندوي الذي أقيم في عام

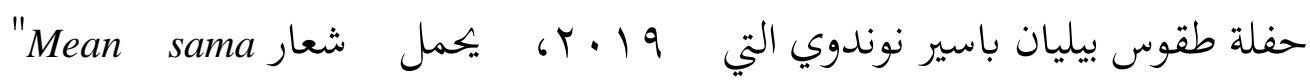

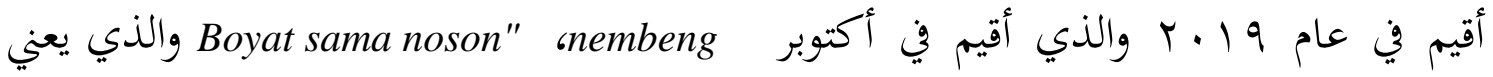

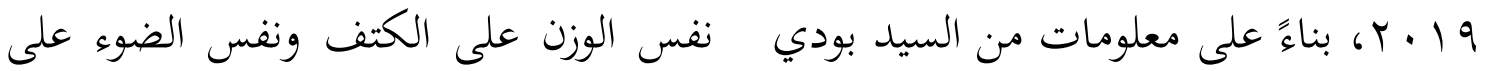


الحقيبة. كل شيء عند القيام به معًا والعمل و والمسيحيين، والكاثوليك، والهندوس، والبوذيين

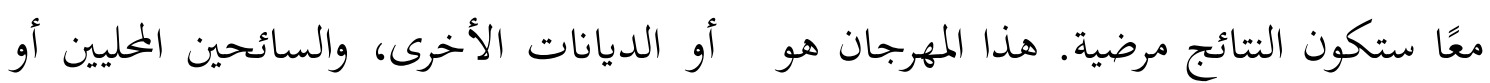

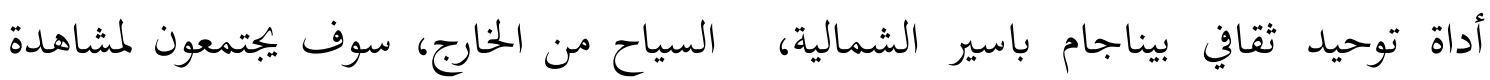

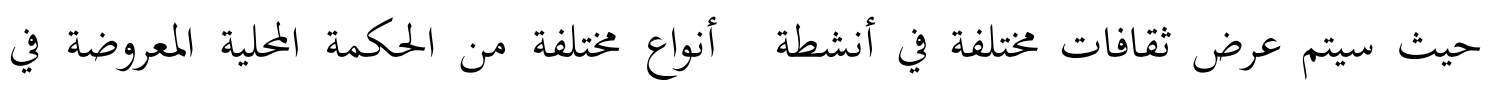
الحفلة. ليس فقط قبلة باسير ولكن سيتم تقديم حفلة طقوس بيليان باسير نوندوي. لديهم

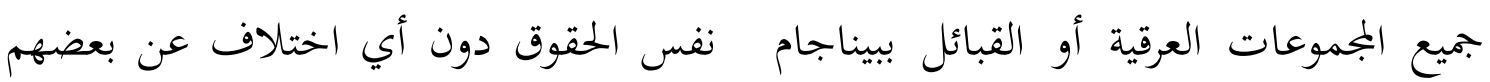

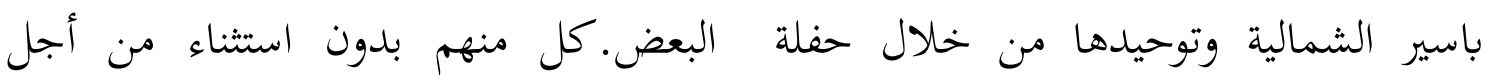
سلامتهم من خلال سيدعو بسويونج الذي بلمي نوندوي. يغنيه المولونج في طقوس بيليان نوندوي. على الرغم من أنه في الحقيقة، فإن غالبية بجتمع باسير يلتزمون بالإسلام، وبشكل عام المولونج الذين يقودون الطقوس هم من لين لئن المسلمين، ولكن عندما يدعو بسويونج فإنه يدعو لجميع الجمهور دون تمييز بعضهم

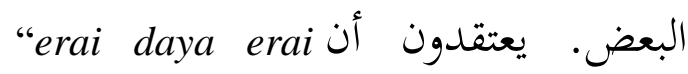

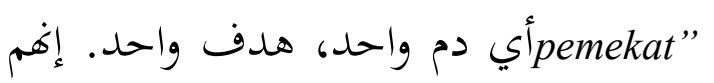
يعتقدون أننا جميعًا متماثلون، أي لدينا دم أحمر ولدينا نفس الهدف، وهو أن نكون شاكرين لله سبحانه وتعالى. لذا سواء أدركت ذلك أم لا، فإن قيم الوسطية الدينية لا تزال ينصهر في بيليان باسير نوندوي.

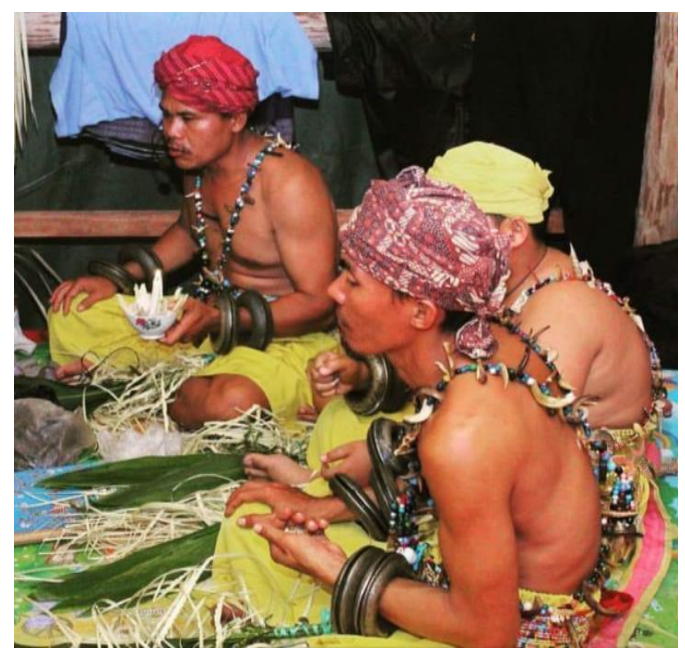
صورة : الصورة الأكبر لموكب طقوس بيليان (الوثيقة :بيدا ريانسياه) خلال حفلة طقوس بيليان باسير نوندوي، سيجتمع الناس في كوتا ريكان تاتاؤ Kuta Rekan Tatau الحفلة. بدءًا من الأطفال إلى البالغين، والرجال والنساء، والسكان الأصليين أو المهاجرين،

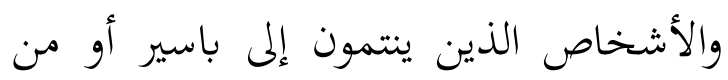

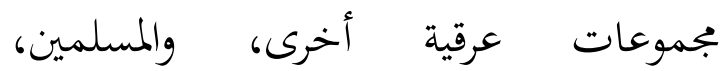


بسويونج. ويقصد في سويونج أن يدعو جميع

البشر من الأطفال حنى الكبر، الرجال

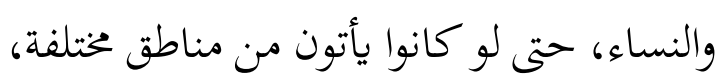
قبائل مختلفة وديانات مختلفة وثقافات مختلفة، لكنها تبقى واحدة وسوف يدعو الجميع من أجل سلامته. البشر بشكل عام في سويونج تشبيه بشجرة التنبول، التي لن تكون ثمارها بالتأكيد كبيرة أو صغيرة، لكنهم متحدون في بني مجموعة واحدة.

طقوس بيليان نوندوي هو الحكمة المحلية الكبرى السن في كاليمانتان. في إطار الحفاظ عليها، التنفيذ لتقليد باسير ،وخاصة بيليان نوندوي من قبل الحكومة في اللائحة الإقليمية لمنطقة بيناجام باسير الشمالية رقم بليل لعام V . V. . . وقد كان جدول أعمال الحفلة السنوية للحكومة منذ عام ه 1 . . . هذا الحفلة هو أداة توحيد ثقافي ببيناجام باسير الشمالية.

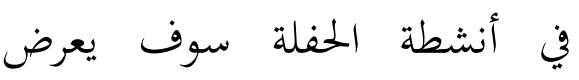
بجموعة متنوعة من الثقافات. ليس فقط بجموعة باسير العرقية ولكن سيتم تقديم جميع المجموعات العرقية أو القبائل ببناجام باسير الشمالية وتوحيدها من خلال هذه حفلة نوندوي. خلال حفلة بيليان باسير نوندوي Kuta سيجتمع الناس في كوتا ريكان تاتاؤسيان Rمekan Tatau الأطفال إلى البالغين، رجالاً ونساءً، من من الحفة، من

الحكمة المحلية لمجتمع باسير الذين يتجهون نحو الوسطية الديني في طقوس بيليان باسير نوندوي أو المشهورة باسم بيليان نوندوي. حاليًا نوندوي هي طقوس سنوية تقيمها الحكومة (وزارة الثقافة والسياحة) بالتعاون مع المؤسسات التقليدية الباسيرية بمنطقة بيناجام باسير الشمالية. قام طقوس بيليان باسير نوندوي لمدة

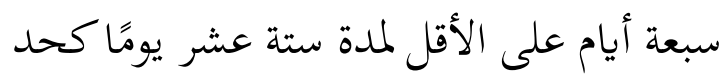
أقصى بقيادة مولونج كشكل من أشكال

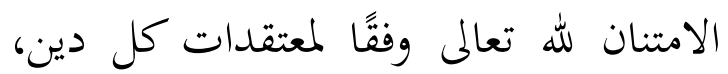
حيث في الطقوس، سيدعو مولونج بسويونج ولقاء المخلوقات غير مرئية واطلب منهم حراسة وعدم إزعاج أي شخص حاضر في الحفلة أو في المنطقة. قيمة الوسطية الدينية من خلال طقوس بيليان نوندوي، من الناحية العملية، فإن الأشخاص الذين يمارسون الطقوس سيقومون بإعلام ودعوة جميع عناصر المجتمع دون التمييز ضد بعضهم البعض. على الرغم من أغم من قبائل وديانات ولغات مختلفة وما إلى ذلك، سيتم دعوقم جميعًا. وعندما وقع طقوس بيليان نوندوي، سيدعو مولونج 
خلال توفير التسهيلات، مثل استكمال جميع الاحتياجات المطلوبة في موكب بيليان باسير نوندوي بالإضافة إلى تسهيلات مولونج لتحويل خبراتم إلى الجيل القادم. r. يجب تطوير البحث حول الحكمة المحلية للناس بكاليمانتان ونشر نتائج البحث في م المكتبات المختلفة لاستخدامها كمؤلفات بحثية إضافية. ع. تحتاج الوزارة الدينية إلى جعل جوهر

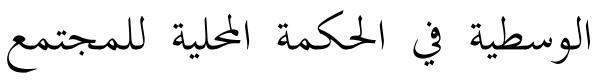

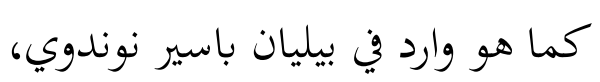
وما إلى ذلك، باعتباره المادة الرئيسية لتجميع مواد القراءة حول الوسطية لئيارة المادة الرئية الدينية.

\section{قول الشكر}

فبهذه المناسبة، فقدمت الكاتبة جزيل الشكر وأجل التقدير بعد الشكر لله إلى كل من يساهم ويشارك في إتمام هذه المقالة البسيطة، وأخص بالذكر: لرئيس مركز ديني للبحوث والإنماء بمكاسار الدكتور سفرالله الذي كلف بإجراء هذا البحث. إلى المشرف الدكتور قادر م الذي قد قام بتوجيه الكاتبة في

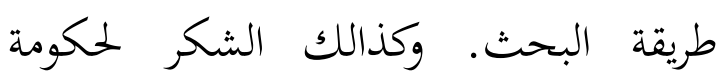
مقاطعة كاليمانتان الشرقية، وحكومة بيناجام
السكان الأصليين أو المهاجرين، أفراد قبيلة

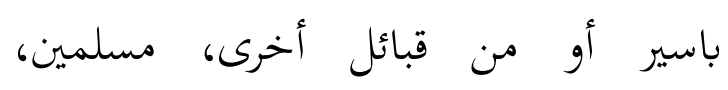
مسيحيين، كاثوليك، هندوس، بوذيين أو من أتباع ديانات أخرى، سياح محلين أو سائحين

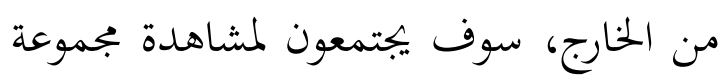
متنوعة من الحكمة المحلية المعروضة في حفلة

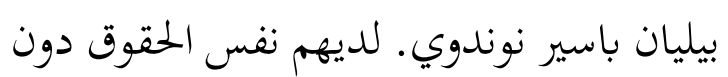
أي اختلافات عن بعضها البعض. سيتم جميعًا

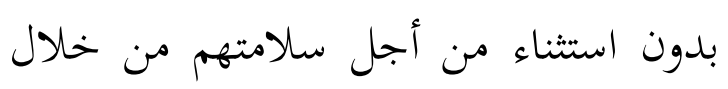

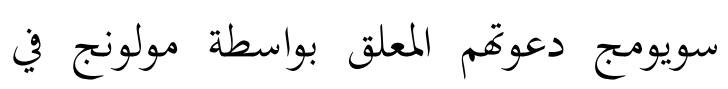
طقوس بيليان نوندوي. التوصيات من نتائج هذا البحث تقدم عدة أشياء كمواد للسياسة، من بين أمور أخرى: 1. يجب نشر المعلومات حول بيليان باسير نوندوي من خلال وسائل

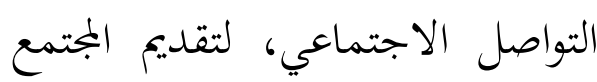

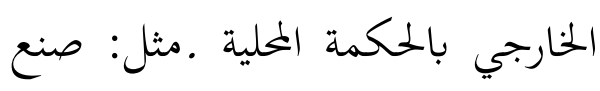
فيلم قصير عن موكب طقوس بيليان

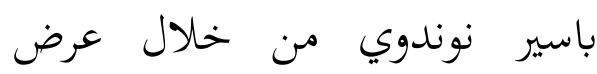
جوانب القداسة ذات الصلة بقيم الوسطية الدينية. Y. هناك حاجة لزيادة اهتمام الحكومة المحلية بالحفاظ على تقليد باسير من ترياد اهنمام الهردة 
باسير الشمالية، والوزارة الدينية ببناجام باسير ورئيسة الأبحاث وردية حامد. وكل الأشخاص

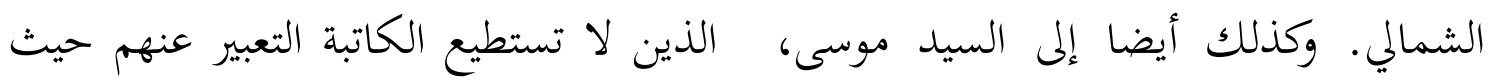

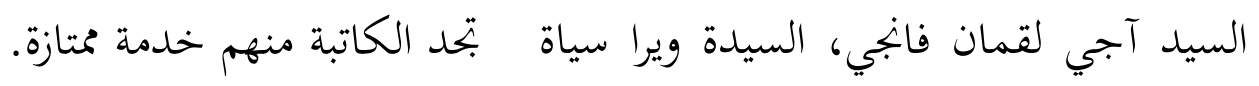
سانتي الذين ساعدوا في جمع البيانات في الموقع. أيضا بمساعدة المنسق الميداني لمركز ديني

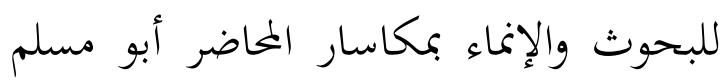




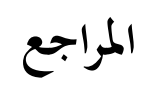

Agama, B. L. dan D. K. A. R. (2013). Moderasi Beragama. In Journal of Chemical Information and Modeling (Vol. 53, Issue 9). https://doi.org/10.1017/CBO978110741 5324.004

Arifin, M., Sukapti, B, J., Saleh, M. H., Juwita, R., \& Azis, A. (2010). Seni Budaya Kalimantan Timur. PT. Hamudha Prima Media.

Assegaf, A. . (1982). Sejarah Kerajaan Sadurengas Atau Kesultanan Pasir. Pemerintah Daerah Kabupaten Derah Tingkat II Pasir.

Ayub, A. (2010). Asal Usul Paser dan RajaRajanya.

BPS Kabupaten Penjam Paser Utara. (2019). Kabupaten Penajam Paser Utara dalam Angka. BPS Penajam Paser Utara.

BPS Penajam Paser Utara. (2019). Kabupaten Penajam Paser Utara Dalam Angka 2019. BPS Penajam Paser Utara.

Dinas Kebudayaan dan Pariwisata Kabupaten Penajam Paser Utara. (2018). Pokok Pikiran Kebudayaan Daerah (PPKD) Kabupaten Penajam Paser Utara.

Dokhi, M., Siagian, T. H., Sukim, Wulansari, I. Y., Hadi, D. W., \& Sambodo, N. (2016). Analisis Kearifan Lokal Ditinjau dari Keragaman Budaya. Pusat Data dan Statistik Pendidikan dan Kebudayaan, Kemendikbud.
Iqbal, M. I. (2001). Budaya dan Sejarah Kerajaan Paser. PT.BHP Kendilo Coal Indonesia dan BLHI.

Kristanti, R. (2019). Besoyong Dalam Pesta Adat Belian Paser Nondoi di Kabupaten Penajam Paser Utara Kalimantan Timur. Selonding, 14(14), 2148-2160. https://doi.org/10.24821/selonding.v14i1 4.3139

Meliono, I. (2011). Understanding the Nusantara Thought and Local Wisdom as an Aspect of the Indonesian Education. International Journal for Historical Studies, Vol. 2(2), 221-234.

Muslim, A., Idham, \& Subair, M. (2019). Iko Iko Siala Tangang (Tracing Moderatism of Religious Concept From the Oral Traditions of Bajau.

Mustikawati, A. (2019). Jejak Budaya Penajam Paser Utara dalam Cerita Asal Usulnya. LOA, 14(1), 45-54.

Panji, A. L. (2019). Mahir Berbahasa Paser, Upaya Pelestarian Bahasa Paser di Zaman Milenial. CV. Kaffah Learning Center.

Rukmana, G. M., \& Hamdani. (n.d.). Analisis Konteks Naskah Kesenian Daerah Kalimantan Timur. Bidang Kebudayaan Dinas Pendidikan dan Kebudayaan Provinsi Kalimantan Timur.

Shihab, M. Q. (2019). Wasathiyyah, Wawasan Islam tentang Moderasi Beragama. PT. Lentera Hati.

Yin, R. K. (1996). Studi Kasus Desain \& Metode (1st ed.). PT Raja Grafindo Persada. 